\title{
La relevancia de respetar el derecho a la jornada máxima de trabajo en la actualidad $\left.{ }^{*}\right)$
}

\section{The importance of respecting the maximum working hours in the present day}

\author{
Daniel Ulloa Millares ${ }^{(*)}$ \\ Pontificia Universidad Católica del Perú
}

\begin{abstract}
Coketown, ciudad de ladrillos rojo y negro, de maquinaria y chimeneas altas, de canal negro y río de extraño color morado, con calles iguales, personas iguales que hacen el mismo trabajo, con días iguales y años iguales.
\end{abstract}

Charles Dickens, Tiempos difíciles

\begin{abstract}
Resumen: La protección del derecho a la jornada máxima de trabajo, prevista hace cien años en el primer convenio de la Organización Internacional del Trabajo y luego incluida en las más importantes normas internacionales ratificadas por Perú, no consigue consolidarse en la práctica, a pesar de que su relevancia no ha cambiado. Creemos que hablar del derecho a la desconexión digital no es sino una ratificación de la importancia de aquel concepto, el cual busca describirse en el presente artículo.
\end{abstract}

Palabras clave: Derecho Laboral - Jornada de Trabajo - Importancia - Excepciones Derecho del Trabajo - Historia del Derecho

\begin{abstract}
The right to a maximum working hours per day (or week) was recognized a century ago in the first convention of the International Labour Organization and has been included in the most important international conventions adopted by Peru. However, it has not been able to consolidate, even though its relevance has not changed. We believe that the right to digital disconnection is a confirmation of the importance of said concept, which we shall describe in this work.
\end{abstract}

Keywords: labour Law - Working Day - Importance - Exceptions - Labor law - History of law

$\left({ }^{*}\right) \quad$ Nota del Editor: el artículo fue recibido el 20 de febrero y su publicación fue aprobada el 4 de mayo de 2019.

${ }^{* *}$ Abogado. Doctor en Derecho y Master Interuniversitario en Empleo, Relaciones Laborales y Diálogo Social en Europa por la Universidad de Castilla-La Mancha, España. Profesor ordinario de Derecho Laboral en la Facultad de Derecho de la Pontificia Universidad Católica del Perú (2001 a la fecha). Director de la Maestría de Relaciones Laborales de la indicada universidad (2014 a la fecha) y profesor de Derecho del Trabajo en la Universidad Nacional Mayor de San Marcos (2017-2018). Presidente de la Sociedad Peruana de Derecho del Trabajo y de la Seguridad Social (2017-2019). Socio de Prelle y Ulloa Abogados. Correo electrónico: dulloa@pyu.pe 


\section{Introducción}

Tal como se señala en la cita del texto de Dickens, la generalizada homogeneidad del trabajo generado por la primera revolución industrial supuso que los trabajadores plantearan reclamos similares, siendo uno de los más comunes el de la limitación diaria y semanal de la jornada de trabajo, el cual fue aceptado sin mayor discusión y cuya vigencia (en teoría) se mantiene hasta ahora. Empero, la globalización de la economía, los cambios en las formas de trabajo, el auge del trabajo "autónomo" y la aparición de la robótica y las "nuevas tecnologías" hacen que nuevamente se cuestione la exigibilidad de este precepto, a pesar de que las personas que trabajan siguen siendo las mismas de carne y hueso. El presente artículo busca repasar la importancia de la aplicación real del derecho a una jornada máxima de trabajo a favor de todos quienes prestan servicios a otro, inclusive sin importar si califican o no jurídicamente como trabajadores.

\section{Relevancia de limitar el tiempo dedicado al trabajo. Sus inicios}

El tiempo de trabajo es un elemento esencial del contrato laboral(1), pues es la determinación cuantitativa del objeto de dicho contrato y constituye, además, un derecho fundamental reconocido a nivel internacional(2), uno de los primeros que sustenta la especialidad del Derecho del Trabajo. Si revisamos nuestra historia podemos rescatar una biografía poco mencionada en el derecho laboral peruano que nos puede ayudar a valorar esta diferenciación y que, además, describe la terrible situación vivida antes de la regulación. Una biografía, además, de una mujer.

Flora Tristán ${ }^{(3)}$ estuvo muy comprometida con la defensa de los derechos de las mujeres y de las personas que tenían que trabajar para vivir (de joven había laborado como obrera colorista en un taller de litografía), hecho que le llevó a escribir un diario muy interesante que relata las peripecias que sufrió mientras difundía en Francia, entre los años 1843 y 1844, su obra titulada "Unión obrera". Ese diario quedó inconcluso pues Tristán murió de tifus en 1844, pero en él se relata la forma en que trabajaban las personas que ella visitaba y con las que conversaba para tratar de convencerlas de unirse con los demás obreros y así aplicar en la práctica sus ideas, las mismas que luego Engels y Marx resaltarán en su libro "La sagrada familia" (1971, capítulo IV, parte I). El diario se titula "El tour de Francia" y en él podemos encontrar descripciones como la siguiente:

"Lo que impide a los obreros actuar en vista a su mejoramiento, es principalmente la falta de tiempo. Veo aquí una docena de personas que tienen el más grande deseo de servir a la causa, pero ¿cómo encontrar una hora libre? Todas son absorbidas por sus ocupaciones cotidianas de trabajo. ¡Es necesario trabajar doce a quince horas sobre veinticuatro para poder comer! ¡Qué galera! Ni un instante para pensar, para leer, para descansar, para conversar con un amigo. Una vida tal embrutecería a Dioses mismo. Un trabajo penoso, forzado y repugnante, penas amargas, enfermedades frecuentes, contrariedades incesantes, una inquietud permanente por la suerte del día siguiente, una fatiga física constante -he aquí la triste existencia del obrero" (Tristán 2006, 100).

(1) Elemento esencial en la trascendencia de lo que regula, pero no en la acepción de "elemento esencial" tal como lo utiliza la mayoritaria doctrina latinoamericana para definir cuándo nos encontramos ante un contrato de trabajo, aspecto en el cual los elementos esenciales son tres: la prestación personal, la remuneración y la subordinación (o ajenidad en España). Véase la Recomendación No. 198 de la Organización Internacional del Trabajo (OIT).

(2) No solamente por normas internacionales sino también por esporádicos acuerdos colectivos. Por ejemplo, el 18 de febrero de 2015, la empresa española Gamesa corporación tecnológica S.A. y las sociedades integradas en el grupo firmaron un acuerdo laboral global sobre responsabilidad social con la representación social e IndustriALL Global Union como sindicato global en que se encuadra la actividad industrial de Gamesa, en el cual mencionan que "la jornada de trabajo, el tiempo de descanso y vacaciones y el salario forman parte de estos derechos fundamentales" a ser reconocidos por la parte empleadora y a cumplirlos según las normativas locales Y si estas se sitúen por debajo de las normas internacionales, aplicarán estas últimas. Es el primer acuerdo en el mundo firmado por una empresa del sector de las energías renovables y cuyo texto completo se puede revisar en el siguiente enlace: http://mcaugt.org/documentos/0/doc13909.pdf (última revisión: 20 de diciembre de 2018).

(3) La importancia de Flora Tristán para el derecho laboral no es un tema que hayamos encontrado muy abordado por la doctrina peruana. Sin perjuicio de su conocido libro Peregrinaciones de una paria (1838) cuando uno lee Paseos en Londres (1840), Unión obrera (1843) y El tour de Francia (1844) se percata que muchas de sus ideas respecto del derecho obrero luego se encuentran, casi sin mayor variación, en las obras de Marx o en la parte de derechos sociales de muchas constituciones. Por ejemplo, Flora Tristán señaló en 1843 que "La clase obrera tiene entonces dos importantes reclamos que hacer: 1. El derecho al trabajo; 2. La organización del trabajo" (Tristán 2011, 82). Decir esto en dicha época y siendo mujer (por lo que fue objeto de muchas de las críticas que recibió y de las cuales se queja en sus libros) resulta de enorme valor y realza su labor que esperamos pueda ser estudiada. 
Años más adelante, el historiador británico Eric Hobsbawmn $(2011,213)$ señaló algo similar sobre el trabajo en el siglo XIX:

"Materialmente, es probable que el nuevo proletariado fabril estuviera algo mejor. Claro que no era libre; estaba bajo el estricto control y la disciplina más estricta todavía impuesta por el patrono o sus representantes, contra los que no tenían recurso legal alguno y sólo unos rudimentos de protección pública. Tenían que trabajar las horas y en las condiciones que les impusieran; aceptar los castigos y multas con los que los sancionaban, a la vez que los patronos aumentaban sus beneficios".

Ejemplos de esta drástica situación también la encontramos descrita por varios autores de dicha época aunque recreada de manera ficticia: Dickens (Tiempos difíciles, 1854), Víctor Hugo (Los trabajadores del mar, 1866), Zola (Germinal, 1885), y más cercano a nuestra era Boon (Pieter Daens, 1971) o Vargas Llosa (El paraíso en la otra esquina, 2003), contexto que, tras varias luchas y reclamos, muchas veces reprimidos, generó el surgimiento del derecho obrero, luego denominado derecho del trabajo.

En la realidad peruana de hace más de un siglo también aparecen algunos testimonios de esa penosa situación: "Al comenzar el siglo, en Vitarte trabajábamos unos días de siete de la mañana a diez de la noche, otros días de siete de la mañana a nueve de la noche" (Lévano 1967, 12).

Planteado el problema, esto se resolvió en Estados Unidos en el año 1905 por la Corte Suprema de Estados Unidos de América ${ }^{(4)}$ aunque de manera inversa a lo que podría pensarse. En ese caso el Sr. Joseph Lochner, dueño de una panadería, cuestionó judicialmente una multa de cincuenta dólares que le fue impuesta en el año 1901 por dejar que un trabajador laborase más allá de la prohibición prevista por una ley de Nueva York de 1895 (la Bakeshop Act) que limitaba la jornada de trabajo de los panaderos a diez horas por día y sesenta horas semanales. En primera instancia la Sala de la Corte Suprema de Nueva York de Apelación confirmó la multa en una votación tres-dos. La apelación, resuelta por la Corte de Apelaciones de Nueva York, fue denegada con una votación cuatro-tres. Frente a esto, el Sr. Lochner llevó su caso ante la Corte Suprema de los Estados Unidos, la cual, en una decisión cinco-cuatro le dio la razón y señaló que la ley restringía la libertad para contratar, vulnerando la décimo cuarta enmienda de la Constitución:

"El derecho general a hacer un contrato relacionado con la ocupación profesional (de una persona) es parte de la libertad protegida por la decimocuarta Enmienda, e incluye el derecho a comprar o vender (libremente) mano de obra excepto (en los casos) controlados por el Estado en el legítimo ejercicio de su potestad de policía.
La libertad de contratación relacionada con la mano de obra incluye a sus dos partes; una tiene tanto derecho a comprarlo como la otra a venderlo.

La salud no es motivo suficiente para interferir en la libertad de una persona o en el derecho al libre contrato fijando las horas de trabajo en el oficio de panadero. Ni se puede justificar una ley que limite esas horas de trabajo (como) una ley sanitaria para salvaguardar la salud pública o la salud de los individuos dedicados a esa ocupación.

La sección 110 del estatuto de trabajo del Estado de New York, que establece que no se exigirá ni permitirá a ningún empleado trabajar en las panaderías más de sesenta horas a la semana ni diez al día, no es un ejercicio legítimo de la potestad de policía del Estado, sino una interferencia irrazonable, innecesaria y arbitraria con el derecho y libertad del individuo a contratar (su) trabajo, y por tanto (la ley) está en conflicto con la Constitución Federal y queda anulada por ésta" (Grau y Martínez 2011).

El contenido de esta decisión, tan cuestionable para algunos (o muy interesante para otros), definió un periodo en la historia judicial estadounidense, la denominada "era Lochner" por la sentencia antes citada, donde existió un claro enfrentamiento entre el constitucionalismo y la democracia, y en el cual un agresivo Tribunal Supremo invalidó varias leyes reguladoras y redistributivas (Slagstad y Elster 1999).

Dado este devenir histórico no es casualidad ( $\mathrm{y}$, además, supone una clara muestra de decisión política) que el primer convenio internacional aprobado por la OIT haya sido el que regule el tiempo de trabajo en las industrias, quizás uno de los lugares donde existía en mayor parte una homogeneidad en la labor a realizar, tal como describía Dickens en la cita que inicia este artículo, y cuya práctica incomodaba y perjudicaba a los trabajadores, lo cual los motivaba a la insurrección.

(4) Tal como lo reseñan Grau y Martínez (2011). 
Este tiempo de trabajo, luego limitado en su extensión, tiene una enorme importancia en el desarrollo de la persona. Como certeramente señalan Monereo y Gorelli $(2009,8)$, "el tiempo penetra en la relación de trabajo e influye en los demás ámbitos del tiempo vital, pues su delimitación incide en los modos de vida, en las relaciones familiares y en el ocio. El tiempo de trabajo determina el tiempo libre."

En efecto, el reconocimiento que todo individuo tiene derecho a la vida, a la libertad y a la seguridad de su persona ha sido una constante en el siglo pasado. Así lo establece el artículo 3 de la Declaración Universal de los Derechos Humanos firmada en 1958. No hay libertad ni vida si cada individuo no es dueño de su tiempo o si el trabajo le quita gran parte de él.

De repente siguiendo esta idea es que la Constitución Política del Perú de 1993 prevé en su artículo 1 que "La defensa de la persona humana y el respeto de su dignidad son el fin supremo de la sociedad y del Estado" y en el numeral 1 de su artículo 2 que "toda persona tiene derecho a la vida, a su identidad, a su integridad moral, psíquica y física y a su libre desarrollo y bienestar".

Queda claro que iniciar una relación laboral en la cual el trabajador se subordina a su empleador, supone una importante restricción para el ejercicio del derecho a la vida o al libre desarrollo de la personalidad pues su disfrute resultará atenuado o afectado por el ejercicio del poder de dirección del empleador. En este sentido, uno de los elementos que necesariamente será regulado por el contrato es el de la distribución u organización de su tiempo, pues parte de la vida del trabajador tendrá que ser dedicada inevitablemente para prestar servicios para otro.

Asimismo, este tiempo dedicado generará una enorme influencia en la salud del trabajador, pues tal como señala el especialista argentino y doctor en ciencias sociales del trabajo Julio César $\mathrm{Neffa}^{(5)}$, la centralidad del trabajo es tan grande que el impacto que tiene sobre las personas afecta directamente su salud a corto, mediano o largo plazo, siendo la intensidad del trabajo, la carga horaria, el control de las emociones (el miedo o riesgo diario de un vigilante o de un conductor por ejemplo), los conflictos éticos y de valores (en muchas profesiones hay que controlarse y hasta fingir estados de ánimo, por ejemplo en un call center o quien trabaje con público), las relaciones sociales en el trabajo y las relaciones con la jerarquía, la autonomía y el control que tiene el trabajador, algunos de los factores más relevantes que inciden en aquella.

Por otro lado, ese tiempo será, muchas veces, el parámetro de medida de la remuneración del trabajador (Monereo y Gorelli 2009, 94-99), por lo que resulta entendible que el empleador también lo quiera organizar y, si es posible, de manera flexible y unilateral, para así maximizar el dinero que está obligado a otorgar.

De ahí que resulte lógico que en el periodo anterior a la existencia de la normativa sobre el trabajo subordinado el contratante de servicios (hoy empleador) busque obtener la mayor cantidad de horas a menor precio y que el prestador de servicios persiga lo contrario: ganar mucho trabajando poco. En esa época se impondrá el primero gracias a la violencia: "la regulación de la jornada de trabajo se presenta como lucha en torno a los límites de la jornada de trabajo, lucha entre el capitalista global, esto es, la clase de los capitalistas, y el trabajador global, la clase obrera" (Marx 2013, 163). Impuesta la regulación de los límites, los intereses opuestos se mantienen aunque algunos prestadores de servicios no los respeten por sus ansias de ascender o ganar más dinero (con trágicas consecuencias como veremos más adelante) o porque también el discurso social ha variado(6).

(5) Entrevista publicada en el diario "La Nación" de Argentina el 17 de mayo de 2015, que se puede leer en http://www.lanacion.com. ar/1793628-julio-cesar-neffa-la-centralidad-del-trabajo-es-tan-grande-que-puede-afectar-a-la-salud (última revisión: 20 de diciembre de 2018).

(6) Desde diferentes corrientes se intenta "deslaboralizar" al trabajador y eliminar la noción de conflicto de las relaciones laborales, señalando que las empresas tienen "colaboradores" y que el trabajador debe tener "mentalidad de empresario", esto es este nuevo trabajador:

"Cuida la empresa, los gastos y los clientes como si fueran propios. Está atento a las oportunidades que hagan mejorar los procesos o los negocios y lo comunican para que pueda ser evaluado e incorporado en la empresa. Sabe que la competencia está afuera y que los directivos y él están en el mismo equipo. Un cambio de condiciones por un nuevo trabajo u horario lo verá como una nueva oportunidad de seguir aprendiendo y se compromete con el resultado, disfruta lo que hace y no está pendiente de las horas." (el subrayado es nuestro), a diferencia de un trabajador típico: "caricaturicemos la mentalidad de un empleado típico. Sigue instrucciones, su función no es cuestionar ni proponer, sino hacer el trabajo para el cual fue contratado. Debe cumplir un horario haciendo un trabajo por el cual recibirá a cambio un pago a fin de mes, si le asignan otro trabajo u horario lo resiente. Es muy probable que se sienta la 
Hablaremos entonces del justificado primer límite existente al tiempo de trabajo, esto es, el derecho a una jornada máxima de trabajo y de su relevancia en la vida de todos los que prestan servicios para otro.

\section{El sentido de la jornada máxima}

Tener establecida una jornada máxima de trabajo, ya sea diaria, semanal, mensual o anual busca limitar -con diferentes alcances- el poder del contratante empleador y por ello su definición debería ser equilibrada. Esto es, no incurrir en el error de una sobreprotección que haga muy difícil la actividad empresarial pero tampoco hacerlo tan flexible que se pierda la finalidad protectora del trabajador y del disfrute de su tiempo de no trabajo, más aún cuando globalmente todavía no existe un reconocimiento o una aplicación generalizada de este derecho, tal como lo señala un informe de la agencia de la Unión Europea de derechos fundamentales ${ }^{(7)}$. Dado que desde antiguo ${ }^{(8)}$ se entiende que cada día está dividido en 24 partes (horas) y que cada una de esas partes contiene 60 unidades (minutos), en las primeras regulaciones se entendió lógicamente que el límite debía establecerse tomando en cuenta dichos parámetros, es decir, ser fijado de manera diaria o semanal. Asimismo, la falta de electricidad condicionaba que el trabajo dependiera de la luz solar, lo cual contribuía a que se limitara (de manera natural) su duración y evitar así algún posible abuso.

De este modo, sin límites externamente impuestos (o no exigibles) más que los generados por la naturaleza, el contratante establecía jornadas que incluían el máximo tiempo de trabajo utilizable para luego, con la llegada de la electricidad, incrementar las jornadas diarias de trabajo de 10 a 12 o 16 horas por día dado que el único límite que se podía permitir otorgar al trabajador era el tiempo que, por razones biológicas, debía tomar alimentos o dormir para así recuperar las fuerzas y seguir trabajando (el carácter binario al que se refieren Monereo y Gorelli 2009, 9-18).

Sobre esto es pertinente recordar el caso del empresario y pensador inglés Robert Owen ${ }^{(9)}$, muchas veces citado como ejemplo de modelos educativos o como base del socialismo británico (Lanfranco 2013, 213-236), quien encontró a inicios del siglo XIX -al convertirse en socio y gerente de una gran fábrica de algodón en el pueblo de New Lanark ${ }^{(10)}$, Escocia- una realidad de jornada que consideró rápidamente modificar, estableciendo mejores condiciones de trabajo, entre ellas, reducir el tiempo de trabajo diario a 10.5 horas y prohibir el trabajo de menores de doce años. Owen consideraba y estaba convencido que mejores condiciones de trabajo aumentarían la productividad de los trabajadores y limitar la jornada era una de dichas medidas.

La visión que Owen estableció cuando empezó a dirigir su fábrica en Escocia fue luego acogida por los diferentes movimientos y organizaciones de trabajadores, recogiéndose la idea de la jornada máxima diaria de ocho horas de trabajo, la misma que fue formalizada internacionalmente, como ya indicamos, en el Convenio No. 1 de la OIT y que rigió en Perú unos meses antes, desde el 15 de enero de $1919^{(11)}$.

En efecto, dado que el objeto del contrato de trabajo es algo inseparable de la persona que lo presta, es lógico que se busque (aunque en la práctica no siempre se cumpla)

contraparte con los que dirigen la empresa, trata de sacar el mayor provecho y a la vez de hacer el trabajo justo para cumplir. Siente que hay dos bandos, por un lado ellos, los empleados, y por el otro, los gerentes o dueños. Se trata de un antagonismo natural por las propias funciones. Cuando las cosas no están muy bien tiene que reclamar o protestar para que lo arreglen o cambien la situación, no dejará que se aprovechen de él. No toma riesgos ya que no es su función, eso lo hace el dueño o el gerente. Lo mejor de la semana es el viernes en la tarde y lo peor es el lunes por la mañana. Esa es una caricatura de lo que más o menos podría sentir un empleado" (Llosa 2015, 43).

(7) El informe difundido en junio de 2015 señala que a pesar de que la legislación de la Unión prohíbe la explotación laboral, los trabajadores migrantes siguen laborando bajo condenables condiciones pues, por ejemplo, perciben bajos ingresos ( 1 euro por hora de trabajo o menos), laboran 12 o más horas durante 6 o 7 días a la semana, etc. El informe (en inglés) se puede encontrar en el siguiente enlace: http://fra.europa.eu/en/publication/2015/severe-labour-exploitation (última revisión: 20 de diciembre de 2018).

(8) Se piensa que en el antiguo Egipto ya dividían el día en veinticuatro horas, si bien algunas de ellas tenían una duración diferente a las otras. Asimismo, no es casual que el sistema decimal se pueda basar en el número de los dedos de las manos y el sistema duodecimal en el número de falanges de cada mano.

(9) La página web de su museo se puede revisar en http://robert-owen-museum.org.uk/ (última revisión: 20 de diciembre de 2018).

(10) New Lanark es un pueblo que actualmente es patrimonio de la humanidad por la UNESCO que está situado a la orilla del río Clyde (para aprovechar su energía hidráulica) que fue fundado en 1785 por el suegro de Owen, David Dale, para albergar fábricas de algodón y residencias para los obreros. Owen las compró en 1799.

(11) Ello en virtud del Decreto Supremo del 15 de enero de 1919 que estableció en ocho horas el tiempo máximo de trabajo diario para los talleres del Estado, ferrocarriles, establecimientos agrícolas y obras públicas ejecutadas por el Gobierno, así como en las empresas particulares, manteniéndose el monto de los salarios vigentes en ese momento. 
que el trabajo no sea tratado como una mercancía pues ello afecta no solo el rendimiento sino también la dignidad de quien lo presta, esto es, los límites físicos y morales de los que hablaba Marx $(2013,160)$. Aunque también es pacífico entender que en la actualidad la organización jurídica del tiempo de trabajo ya no puede ser la misma que la de la época de la industrialización (Monereo y Gorelli 2009, 13), si resulta válido mantener la defensa del concepto de tiempo individual y social vivible ${ }^{(12)}$.

No obstante el largo camino recorrido y a casi cien años de la existencia de este límite, el mismo, lamentablemente, no es cumplido en la realidad. En fines del año 2014 pudimos conocer un reportaje de la $\mathrm{BBC}^{(13)}$ que describía la existencia de precarias condiciones de trabajo en las empresas que fabrican los productos marca Apple en China: Un reportero de la BBC se hizo pasar como trabajador y filmó la línea de producción de los iPhone, teniendo que laborar dieciocho días consecutivos. En ese lapso muchos trabajadores fueron filmados quedándose dormidos, dado que la jornada diaria normalmente era de doce horas, sin tener reconocimiento de horas extras. Apple señaló que iba a investigar estos hechos.

Asimismo, hace poco se detalló la situación del trabajo migrante en España, donde las mujeres tienen que laborar en las principales ciudades del país por jornadas de once horas diarias $^{(14)}$

Por otro lado, desde 1969 se estudia y se analiza en Japón el concepto de karoshi (morir por realizar exageradas jornadas en sobretiempo) así como el karojisatsu (suicidio por razones de sobretiempo y situaciones laborales estresantes). Estos temas, de gran relevancia en dicho país y que han supuesto recientemente la aprobación de una ley para limitar el número de horas extras ${ }^{(15)}$ a cien mensuales a partir de abril de 2019 en las grandes empresas y en abril de 2020 en las pequeñas y medianas, han sido objeto de otro trabajo (véase Ulloa 2016).

Y en lo referido a los trabajos para plataformas, un reciente testimonio publicado por un rider de Glovo en España ${ }^{(16)}$ ratifica que en ese tipo de trabajo, no cubierto por el derecho laboral, "somos nosotros los que perdemos tiempo y dinero", pues "Más que libertad, es una cuestión de elección: la elección de hacer exactamente lo que la empresa quiere, o perder tiempo y dinero", sin que puedan existir facilidades para alguna comunidad de intereses o defensa sindical, pues estas empresas (Uber, Airbnb, Amazon Flex, Wework, etc.) incentivan a sus prestadores "a competir unos con otros a través de puntuaciones que dictan cuándo podemos trabajar y cuánto trabajo tenemos durante nuestros turnos de trabajo. Como mi jefe nos dijo a mí y a otro posible mensajero de Glovo: 'Sois compañeros de trabajo, claro, pero también sois competidores', una filosofía que invade todos los aspectos de nuestro trabajo."

En las siguientes líneas evaluaremos si la limitación del tiempo de trabajo debe continuar siendo un imperativo o, considerando las diversas excepciones existentes y las variadas formas de trabajo vigentes que resultan diferentes respecto a las del siglo pasado, pueda ser más pertinente aceptar o permitir que algunos trabajadores tengan la posibilidad de disponer de este límite, quedando descartado que sea el empleador o el legislador quien lo imponga o decida, salvo razones excepcionales, como veremos más adelante.

Queremos resaltar que en un reciente informe preparado por la Comisión Mundial sobre el Futuro del Trabajo establecida por la $\mathrm{OIT}^{(17)}$ (que fue presentado el 22 de enero de 2019 para ser sometido a consideración de la reunión del centenario de la Conferencia Internacional del Trabajo en junio de 2019) se estableció como un elemento para aumentar la inversión en las instituciones del trabajo, ampliar la soberanía del trabajador sobre su tiempo, esto es, permitir a los trabajadores "elegir los horarios de trabajo, sujetos a las necesidades que tenga la empresa de una mayor flexibilidad" y atender los casos de las personas que trabajan "por llamada" o en

(12) Ya viene siendo usual que se discuta la existencia de una jornada máxima diaria de cuatro horas o que se labore solamente cuatro días a la semana. Sobre esto se puede revisar, entre otros, Bregman (2016, 119-139), Ferris (2016, 53-64), Frayne (2015, 45-56), Harari (2018, 38-64).

(13) Ver http://www.bbc.com/news/business-30540538 (última revisión 20 de diciembre de 2018).

(14) Ver https://elpais.com/ccaa/2018/12/28/madrid/1545991834_345040.html (última revisión 28 de diciembre de 2018).

(15) Ver noticia en el siguiente enlace: https://www.lainformacion.com/mundo/japon-se-pone-manos-a-la-obra-y-reforma-una-ley-paraeliminar-el-exceso-de-trabajo/6351369/ (última revisión 4 de mayo de 2019).

(16) Ver el siguiente enlace: https://www.elsaltodiario.com/glovo/tres-meses-infiltrado-glovo.gig.economy-mensajeria (última revisión 4 de mayo de 2019).

(17) Cuyo texto completo puede consultarse en este enlace: https://www.ilo.org/wcmsp5/groups/public/---dgreports/---cabinet/documents/ publication/wcms_662442.pdf (última revisión 4 de mayo de 2019). 
labores "de guardia" (OIT 2019, 42). Esto es, la OIT no opta por defender los límites del siglo pasado sino de intentar llegar a un acuerdo por el cual el trabajador gobierne su tiempo.

Dada la amplitud del tema, revisemos la regulación peruana referida al contenido del derecho de jornada, no sin antes mencionar, para una simple comparación, que la legislación española basa su regulación de jornada máxima en tres pilares, según el artículo 34.1 del Estatuto de los Trabajadores (Palomeque y Álvarez 2009, 650):

- Cuarenta (40) horas semanales de trabajo efectivo de promedio en cómputo anual como jornada ordinaria máxima(18);

- Nueve (9) horas ordinarias de trabajo efectivo como máximo, salvo pacto en convenio colectivo; y

- Entre el final de la jornada y el comienzo de la siguiente deben mediar por lo menos doce (12) horas (descanso entre jornadas).

\section{La situación peruana}

El tiempo de trabajo está regulado en el artículo 25 de la Constitución Política del Perú de 1993 y su mandato se aplica a todo tipo de trabajo ${ }^{(19)}$ :

"La jornada ordinaria de trabajo es de ocho horas diarias o cuarenta y ocho horas semanales, como máximo. En caso de jornadas acumulativas o atípicas, el promedio de horas trabajadas en el período correspondiente no puede superar dicho máximo.

Los trabajadores tienen derecho a descanso semanal y anual remunerados. Su disfrute y su compensación se regulan por ley o por convenio."

Del primer párrafo de este artículo podemos entender lo siguiente:

1. Hay jornadas ordinarias y jornadas extraordinarias de trabajo. Por tanto, se reconoce tácitamente la existencia (sin límite) del trabajo en sobretiempo u horas extras.

2. La jornada ordinaria de trabajo tiene dos límites, disyuntivos: diario (8 horas) o semanal (48 horas).

3. Se permite la existencia de jornadas acumulativas o atípicas, cuyo número de horas en promedio (semanal porque diario no tendría sentido) no puede superar el límite establecido.

El segundo párrafo establece el derecho a dos descansos remunerados: el semanal y el anual (vacaciones) aunque no fija su alcance temporal, dejando dicha regulación a la ley, así como la de su compensación. De ahí que legalmente se hayan hecho diferencias solo por el hecho si uno labora en una micro empresa o en una pequeña empresa $^{(20)}$.

La Constitución anterior, la de 1979, establecía algo más extenso en su artículo 44 y la citamos porque puede explicarnos la redacción del texto constitucional vigente:

"La jornada ordinaria de trabajo es de ocho horas diarias y de cuarenta y ocho horas semanales. Puede reducirse por convenio colectivo o por ley. Todo trabajo realizado fuera de la jornada ordinaria se remunera extraordinariamente. La ley establece normas para el trabajo nocturno y para el que se realiza en condiciones insalubres o peligrosas. Determina las condiciones del trabajo de menores y mujeres. Los trabajadores tienen derecho a descanso semanal remunerado, vacaciones anuales pagadas y compensación por tiempo de servicios. También tienen derecho a las gratificaciones, bonificaciones y demás beneficios que señala la ley o el convenio colectivo."

Este artículo, en opinión de Pasco (1993, 415-416), "adolece de múltiples errores de concepto $y$, más que progreso social, parecería representar un retroceso por sus imprecisiones y atavismos". El citado autor señalaba como críticas a este texto que (i) se denomine como "jornada ordinaria" lo que debería ser la "jornada máxima

(18) Aspecto que no respeta la normativa europea vigente tal como lo anota Martínez Yañez (2011, 363-370), pues el plazo máximo de referencia previsto en la Directiva 2003/88/CE es de cuatro meses y para casos especiales y normalmente pactados en convenios colectivos, seis y doce meses.

(19) A diferencia de Uruguay, por ejemplo, que tiene diferentes regulaciones sobre jornada máxima para el comercio y administrativos (8 horas diarias y 44 semanales), para la industria (8 horas diarias y 48 semanales) y otros regímenes especiales. Asimismo, la ley fija, en principio, las horas de cierre de los establecimientos comerciales. Véase Pérez del Castillo (2013, 57-66)

(20) Véase el artículo 55 del Decreto Supremo 13-2013-PRODUCE, norma que aprueba el Texto Único Ordenado de la Ley de impulso al desarrollo productivo y al crecimiento empresarial. 
legal", (ii) se use la conjunción "y" antes que la disyunción "o", creando rigidez para la adopción de sistemas flexibles y compensatorios, (iii) no restrinja la duración o repetición de la jornada extraordinaria, (iv) admita la subsistencia de trabajo en condiciones insalubres o peligrosas cuando en realidad debería erradicarlas y (v) siga considerando a la mujer, y no a la madre trabajadora, como sujeto de protección especial, identificándola con el menor de edad.

Como podrá apreciarse del precepto constitucional vigente, no solo se han aceptado la mayoría de las críticas presentadas por Pasco (se ha corregido la segunda, la cuarta y la quinta) sino que la regulación actual es mínima, lo cual debe llevarnos a completar la interpretación del derecho con las fuentes internacionales.

Ello en aplicación del artículo 3, el artículo 55 y la cuarta disposición final y transitoria de la Constitución. Es por esto que creemos fehacientemente que toda norma internacional sobre derechos fundamentales (incluidos los convenios de la OIT) que haya sido ratificada deberá ser utilizada como elemento de interpretación del derecho internamente recogido, en este caso, a la jornada máxima.

Así podemos ver que el derecho en análisis está reconocido de la siguiente forma en las principales normas internacionales ratificadas y, por tanto, vigentes en Perú:

"Declaración Universal de Derechos Humanos ${ }^{(21)}$.

Artículo 24.- Toda persona tiene derecho al descanso, al disfrute del tiempo libre, a una limitación razonable de la duración del trabajo y a vacaciones periódicas pagadas.

Pacto Internacional de Derechos Económicos, Sociales y Culturales ${ }^{(22)}$.

Artículo 7.- Los Estados Partes en el presente Pacto reconocen el derecho de toda persona al goce de condiciones de trabajo equitativas y satisfactorias que le aseguren en especial:

(...) d) El descanso, el disfrute del tiempo libre, la limitación razonable de las horas de trabajo y las vacaciones periódicas pagadas, así como la remuneración de los días festivos.

Protocolo adicional a la Convención Americana sobre Derechos Humanos en materia de derechos económicos, sociales y culturales, Protocolo de San Salvador ${ }^{(23)}$.

Artículo 7.- Condiciones justas, equitativas y satisfactorias de trabajo

Los Estados partes en el presente Protocolo reconocen que el derecho al trabajo al que se refiere el artículo anterior, supone que toda persona goce del mismo en condiciones justas, equitativas y satisfactorias, para lo cual dichos Estados garantizarán en sus legislaciones nacionales, de manera particular: (...)

g) la limitación razonable de las horas de trabajo, tanto diarias como semanales. Las jornadas serán de menor duración cuando se trate de trabajos peligrosos, insalubres o nocturnos;

h) el descanso, el disfrute del tiempo libre, las vacaciones pagadas, así como la remuneración de los días feriados nacionales".

Como podemos observar, todas estas normas no solo prevén el derecho a una limitación razonable de las horas de trabajo, sino que incluyen el derecho(24) (i) al descanso, (ii) a que el tiempo libre deba ser disfrutado, (iii) a vacaciones pagadas ${ }^{(25)}$ y (iv) a feriados remunerados ${ }^{(26)}$ (ausente en la Declaración Universal de Derechos Humanos y presente en las dos últimas).

(21) Representantes de España y Perú firmaron la declaración, aunque este último país también la aprobó el 8 de diciembre de 1959.

(22) Ratificado por España el 17 de abril de 1977 y vigente en Perú desde el 27 de julio de 1978.

(23) Vigente en Perú desde el 27 de abril de 1995.

(24) Sobre la diferencia entre los derechos reconocidos a la persona y los reconocidos al trabajador, véase Ulloa (2013, 101-111).

(25) Entendemos a las vacaciones como aquel derecho que supone disfrutar de un tiempo de descanso que además es pagado. Así lo prevén las legislaciones española y peruana. Por ello, hablar de "vacaciones pagadas" resulta redundante.

(26) Al igual que las vacaciones, un día feriado supone un día de descanso que debe ser incondicionalmente pagado. Por tanto, también entendemos redundante hablar de "feriados remunerados". Otra cosa son los "puentes" o "feriados compensables" (muy frecuentes en Perú en los últimos años) que en realidad no son feriados sino cambios obligatorios de jornada pues son días que el Estado Peruano, sin mayor discusión con los actores sociales, determina como de descanso (por ejemplo, el lunes 24 de diciembre de 2018 , tal como lo reguló el Decreto Supremo 121-2018-PCM publicado el 12 de diciembre de 2018) que luego deben ser recuperados por el trabajador. Y si no hay acuerdo sobre cuando recuperar las horas dejadas de laborar, es el empleador quien decide la oportunidad, generándose así la posibilidad de otro perjuicio a los derechos vinculados al descanso que de repente hacen que el trabajador no quiera descansar el día señalado unilateralmente por el Gobierno. 
No obstante lo indicado en la práctica peruana solamente se enfatizan tres (o de repente dos) de los indicados derechos, los descansos en días feriados y en vacaciones, sin que se encuentre difundido, creemos que por interesada desidia $u$ olvido, un desarrollo o análisis del contenido de los derechos al descanso diario y al disfrute del tiempo libre ${ }^{(27)(28)}$.

Por otro lado, otra norma internacional de mucha aplicación en la jurisprudencia peruana, a pesar de los problemas generados por su antigüedad, es el Convenio OIT No. 1. Como sabemos, este convenio (aplicable solamente al sector industrial, pues el referido a oficinas, el Convenio OIT No. 30, no ha sido ratificado por nuestro país) establece dos límites, diario y semanal, y también presenta algunas excepciones.

Consideramos que lo anterior resulta importante para entender muchas de las características de la regulación del tiempo de trabajo vigentes en Perú como por ejemplo la inexistencia de un límite cuantitativo para el trabajo en horas extras $^{(29)}$, la inexistencia de pausas diferentes al refrigerio en labores con horario corrido, la vigencia de tres colectivos de trabajadores a quienes no se les aplica la jornada máxima, etc.

Pero ¿cómo se originó la situación actual normativa? El siguiente texto nos ilustrará sobre ello.

\subsection{Algo de historia para entender el presente}

Perú fue uno de los primeros países que consagró en sus textos legales la limitación de la jornada de trabajo, pero fue por partes, pues lo hizo como respuesta a varios años de intentos de entender la cuestión social y atender diferentes reclamos obreros que generaban soluciones específicas, no generales ${ }^{(30)}$, siendo que el Decreto Supremo del 15 de enero de 1919, que estableció finalmente la jornada de ocho horas en los talleres del Estado, en sus ferrocarriles, establecimientos agrícolas e industriales y en las obras públicas que ejecute el gobierno, así como a las fábricas, ferrocarriles, establecimientos industriales, agrícolas y mineros de empresas o particulares, fue emitido ${ }^{(31)}$ para solucionar una nueva huelga de obreros ${ }^{(32)}$ y no como parte de una política de Estado.

Según el historiador Basadre (1963, 3199), a fines de agosto de 1896 se produjo una huelga de más de 500 trabajadores en la fábrica de tejidos de Vitarte para pedir aumento de salarios, mejora en la alimentación y el establecimiento racional de las horas de trabajo pues la jornada laboral era de 16 horas y el jornal ascendía a 30 centavos diarios. No hubo resultado. Luego, en marzo de 1901 se celebró en Lima un congreso obrero por iniciativa de Ramón Espinoza y, ante los reiterados reclamos laborales, el 10 de marzo de 1904 el Ministerio de Fomento del Perú encargó al profesor de la Universidad Mayor de San Marcos, Sr. José Matías Manzanilla, la labor de preparar diez proyectos de legislación del trabajo, tratando como temas la higiene y seguridad de los trabajadores, el trabajo de niños y mujeres, el descanso obligatorio, las horas de trabajo, la indemnización por accidentes de trabajo, etc. (Basadre 1963, 3442)(33).

(27) El numeral 20 de la sentencia del Tribunal Constitucional No. 4635-2004-AA (caso Southern) contiene un interesante precepto que debería generar un mayor desarrollo:

"Es evidente que el ejercicio del derecho al descanso y al disfrute del tiempo libre guarda estrecha relación con la implantación de una jornada de trabajo razonable. Entonces, la jornada de trabajo no puede ser un impedimento para el adecuado ejercicio del mencionado derecho o convertirlo en impracticable. Es válido por ello concluir, también, en que las jornadas atípicas deberán ser razonables y proporcionadas según el tipo de actividad laboral, a fin de que el derecho al descanso diario sea posible."

Este caso es el único hasta la fecha en que el Tribunal Constitucional reconoce expresamente el derecho al descanso y al disfrute del tiempo libre.

(28) El profesor Toyama (2015) señala, sin embargo, que actualmente estamos asistiendo a un contexto en el que se toma con mucha importancia la valoración del tiempo libre (descanso efectivo en días feriados y en domingos) como factor de salud y recreación, pues el tiempo de trabajo es actualmente objeto de relevante negociación por las nuevas generaciones. Si bien pareciera sorpresivo que los trabajadores exijan descansar en los días que legalmente le corresponde, la realidad peruana (bajos ingresos e imperatividad empresarial) hacen común que el trabajador labore en esos días sin mayor discusión para así garantizar su estabilidad en el trabajo mediante la renovación de su contrato, así como percibir un ingreso más digno.

(29) Se encuentra pendiente de aprobación en el pleno del Congreso un proyecto de ley para limitar el número de horas extras. Véase el siguiente enlace: https://larepublica.pe/economia/1443858-congreso-limitaria-horas-extras-48-mensuales (última revisión: 4 de mayo de 2019).

(30) Al respecto, véase Basadre (1963, 3438-3455). Para una visión de la vida obrera de inicios del siglo XX en Lima puede revisarse Stein $(1986,11-42)$

(31) Las citas históricas normativas se han tomado de Molina (1950, 291).

(32) No obstante, según Lévano (1967), la jornada de ocho horas ya se había logrado en enero de 1913, consiguiéndola, como es lógico, los jornaleros de la empresa del Muelle y la Dársena del Callao luego de producirse una huelga que hizo que el Presidente de ese entonces, Billinghurst, declare el estado de sitio en Lima y luego formalice la jornada mediante un decreto.

(33) Varios de dichos proyectos terminaron en leyes: Ley 1378 (accidentes de trabajo), Ley 2851 (trabajo de mujeres y niños con jornada máxima de 8 horas diarias y 45 horas semanales), Ley 3010 (descanso dominical obligatorio y feriados). 
Así, el 1 de mayo de 1904, el gremio de jornaleros del Callao reclamó, entre otras cosas, que el día de trabajo se componga de ocho horas útiles de trabajo, de siete a diez y de doce a diecisiete horas (Basadre 1963, 3443). Sin embargo, dicha huelga finalizó el 19 de mayo con un aumento de remuneraciones, pero tampoco sin reconocimiento de la jornada máxima.

Cuenta Lévano (1967, 10-12) que el 1 de mayo de 1905 su abuelo, Manuel C. Lévano, obrero panadero que laboraba doce horas todas las noches, pronunció en Lima su discurso titulado "Lo que son y lo que deben ser las organizaciones obreras en el Perú" en el acto realizado en el teatro Politeama a nombre de la federación de obreros panaderos "Estrella del Perú" reclamando la jornada de ocho horas. Según relata, fue la primera vez que se celebró el 1 de mayo en el país. Y también donde por primera vez apareció la bandera roja según el citado Basadre (1963, 3450).

El 24 de setiembre de ese mismo año, Matías Manzanilla ${ }^{(34)}$ presentó los proyectos de ley encargados por el Gobierno, entre ellos el de accidentes de trabajo y el de fijar en nueve horas la jornada máxima de trabajo. Sin embargo, este último proyecto no fue discutido.

Siempre según Lévano (1967), en el año 1906 se realizó otra huelga en Vitarte, lugar en donde existían numerosas empresas textiles, reclamando la reducción de la jornada de trabajo vigente de doce horas. Luego, en octubre de ese mismo año los obreros del puerto de Chicama y los cañaveleros también reclamaron mejores condiciones de trabajo y fueron reprimidos. Posteriormente, el 1 de mayo de 1908 los portuarios del Callao, Chancay y Huacho realizaron un paro que, con algunas muertes, logró una jornada solamente para ellos de nueve horas. Lo mismo ocurrió con los trabajadores de la empresa Cerro de Pasco Railway, que en junio de 1909 se declararon en huelga para que las horas de trabajo se reduzcan a nueve, cuando en la práctica estas eran de treinta y seis horas consecutivas (Garland citado por Lévano 1967, 23-24).

Resultado de estas presiones fue la aprobación en enero de 1911 de la primera ley sobre accidentes de trabajo, ley 1378 , discutida desde 1905 y reglamentada por decreto de fecha 4 de julio de 1913, que acoge la responsabilidad del empleador por los accidentes que ocurran a sus obreros y empleados en el hecho del trabajo o con ocasión directa de él (Basadre 1963, 3652).

En esa época de lucha hubo también mucha labor de difusión periodística, dado que los obreros necesitaban unificar su lucha al no existir una representación que centralizara sus reclamos. Así, en abril de 1911 se realizó el primer paro general en Lima y Callao en solidaridad por una huelga en Vitarte que reclamaba la suspensión del trabajo nocturno, disminución de las horas de labor (se trabajaba, más o menos, desde las siete de la mañana hasta las nueve de la noche, con una hora de descanso para el almuerzo y otra para la comida; Basadre 1963, 3652) y el aumento del salario en el diurno. Se logró solamente lo primero.

Es muy descriptivo el extenso texto del comunicado titulado "comité de propaganda sindical" de fecha 16 de junio de 1911 y firmado por dirigentes e intelectuales que señalaba, entre otras cosas, la necesidad de la unión sindical y "la reducción a ocho de las horas de labor, la exclusión en los talleres de los niños menores de doce años, la higienización (sic) saneamiento de las viviendas para obreros, la efectividad de las indemnizaciones que la lei (sic) establece para las víctimas del trabajo, la fundación de asilos para los proletarios ancianos ó el establecimiento de seguros de renta para la vejez" (Lévano 1967, 26).

Las ocho horas de trabajo logradas primero en el Callao (empresa Muelle y Dársena, 1913) y luego reclamadas en otros sectores como los obreros de la fundición Smelter, quienes consiguieron en 1916 el régimen de ocho horas de trabajo, fueron objeto de reclamo de otros grupos (por ejemplo, los trabajadores campesinos de Huacho, Sayán, Supe, Barranca y Pativilca, quienes realizaron una huelga con dicho fin), pero también fueron objeto de represión (pues en promedio se trabajaba diez horas diarias) hasta llegar a la huelga iniciada el 12 de diciembre de 1918 por los obreros de la fábrica de tejidos "EI Inca", sumándose a ellos la Unión Textil de Vitarte, fundada por nueve obreros el 26 de mayo de 1911. El 15 de diciembre todos los sindicatos textiles se unieron a la huelga, el 22 se incorporó la federación de panaderos, lo cual obligó al gobierno del Presidente José Pardo a decretar el 8 de enero de 1919 la suspensión de las garantías individuales y ordenar un ataque armado contra Vitarte. Contra ello el 9 de enero se convocó a un paro general nacional, el cual inició el $13^{(35)}$ y que logró paralizar Lima, según indican los

(34) Manzanilla fue, para muchos, el primer gran legislador laboral peruano.

(35) "No se había visto en la capital una situación semejante desde la época de la elección de Billinghurst" siendo que se informaba de "una sangrienta huelga en Buenos Aires que se convirtió, según se dijo entonces, en un formidable movimiento maximalista y revolucionario" (Basadre 1963, 3907). 
historiadores, durante tres días (13, 14 y 15 de enero) porque no hubo transporte, pero sí enfrentamientos entre gendarmes y obreros, lo cual finalizó el día 15 con la entrega del decreto del Presidente a una representación estudiantil universitaria (en la cual estaba Víctor Raúl Haya de la Torre, luego fundador del APRA), aliada de los obreros en la parte final de esta lucha.

Este decreto limitó en ocho el número de las horas de trabajo en los talleres o establecimientos del Estado. En el sector privado debía existir un acuerdo, pero caso contrario, se aplicaba el límite arriba indicado, conservando los obreros el monto de sus salarios. Con ello el paro fue levantado y el jueves 16 de enero la ciudad recuperó su aspecto normal (Basadre 1963, 3908), aunque la huelga continuó en Morococha, Junín.

Posteriormente, el derecho a las ocho horas de trabajo diario (en esa época todavía no existía el derecho al descanso semanal) fue reconocido para otras actividades, a saber:

- Negociaciones agrícolas de los valles de Chicama y Santa Catalina en el departamento de La Libertad (Decreto Supremo del 7 de diciembre de 1921),

- La realizada por los indígenas servidores de la hacienda Lauramarca, Quispicanchis, Cuzco, con excepción de los que realizaban pastoreo o labores de contratos especiales (Resolución Suprema del 11 de mayo de 1923),

- Los empleados de comercio (artículo 55 de la Resolución Suprema del 22 de junio de 1928, reglamento de la Ley 4916, que modificó algunos artículos del Código de Comercio),

- Los que laboraban en zonas petrolíferas (Resolución Ministerial del 19 de mayo de 1931),

- Los que laboraban en las obras que se ejecutan bajo la tuición de las juntas pro desocupados (Resolución Suprema del 21 de julio de 1934),

- Los que realizaban carga y descarga en el puerto del Callao (Resolución Suprema del 23 de octubre de 1934),

- Aplicación en el extranjero de la jornada máxima para el servidor peruano contratado (Resolución Suprema del 23 de marzo de 1936).

La jornada máxima de trabajo de 8 horas diarias se unificó varios años después con lo dispuesto en el artículo 1572 del Código Civil de $1936^{36}$ vigente desde el 14 de noviembre de ese año. Luego, en 1945 se ratificó el Convenio OIT No. 1 mediante Resolución Legislativa 10195 del 23 de marzo, sin que se haya ratificado, como indicamos, el Convenio OIT No. 30. Y hasta hoy la regulación de la jornada se mantiene inalterable en sus dos límites, diario y semanal.

Tenemos entonces un derecho con mucha historia, creado y generado de manera paulatina según lo exigían diferentes sectores de trabajadores que luego se asimiló a lo existente en la normativa internacional de inicios del siglo pasado. Pero es un derecho que, en nuestra opinión, se quedó en dicho contexto, sin haber sido adecuado a las nuevas realidades económicas generando una falta de modernidad de la regulación de la jornada en Perú y su falta de estudio o análisis, aspectos que serán comentados a continuación.

\section{Temas no resueltos en la realidad peruana: la fijación de la jornada y sus posibilidades de variación unilateral}

Tomando en cuenta la importancia del tiempo de trabajo, los antecedentes de su regulación y la normativa actual ¿tiene el trabajador el derecho a que su jornada esté siempre determinada o esta puede depender o ser variada objetiva o subjetivamente por el empleador?

Como hemos visto, las normas peruanas protegen al trabajador señalando que su jornada máxima no debe exceder un número diario o semanal, pero nada se indica sobre la determinación del número de horas de la jornada y si estas pueden ser variadas unilateralmente. Así, la ordenación flexible del tiempo de trabajo y la posibilidad de su distribución irregular en un amplio periodo (un año, tal como ocurre en España), resulta ser una herramienta muy valiosa para el empleador ${ }^{(37)}$ pero que puede resultar lesiva para el trabajador, facilitada además por las

(36) Inicialmente, las normas sobre el contrato de trabajo aparecieron en el Código Civil peruano. Artículo 1572.- El contrato de un trabajo, sea individual o colectivo, supone el pago de salario en dinero efectivo; la jornada máxima de ocho horas de labor; el descanso semanal; la prohibición del trabajo de los menores de catorce años; la limitación del trabajo de los menores de dieciocho años, condicionada a la educación y desarrollo físico; la igualdad del salario, sin distinción de sexo, por trabajo igual y su adecuación a las necesidades de la vida del obrero; la indemnización por accidente; los seguros obligatorios; y la intervención del Estado para asegurar la aplicación de las leyes y reglamentos correspondientes.

(37) Un estudio sobre este tema, parte importante de las reformas realizadas en España en el año 2012, puede leerse en Argüelles Blanco $(2012,11-29)$. 
reformas ocurridas en los últimos años, esto es la denominada flexibilidad interna, vinculadas a la posibilidad de realizar modificaciones sustanciales de las condiciones de trabajo, entre ellas, las del horario y la distribución de la jornada(38).

Ante una norma que fija un tope (un máximo de derecho necesario) resulta dispositivo para ambas partes la delimitación de su número por debajo de ese límite. La duda que surge es si el empleador (dada la imposibilidad del trabajador, al estar subordinado) puede modificar la jornada una vez fijada. Y ello es más significativo si, tal como lo previó originalmente la Ley 11/1994 española, se permite que la distribución irregular de la jornada en un año debía establecerse por convenio colectivo o por acuerdo entre el empleador y los representantes de los trabajadores, respetando siempre los descansos diarios y semanales. Esto es, allá se optó por un procedimiento intermedio entre la voluntad del empleador y la voluntad del trabajador entendiéndose que mediante la negociación colectiva se podía alcanzar un equilibrio entre los intereses de ambas partes.

Esta situación genera una mayor preocupación en la exigencia de una pausa entre jornada y jornada, lo cual no existe en Perú porque el límite de la jornada solamente es diario o semanal. Por tanto, pensar en una forma de cálculo anual no parecería ser necesario pues el sistema peruano, con sus excepciones y la falta de límite del trabajo en horas extras, ya resulta claramente flexible para el sector empresarial.

Pero la flexibilidad en este tema tiene otras manifestaciones que todavía no se presentan en Perú. Al respecto podemos observar que desde hace varios años existe en Reino Unido el "zero hours contract", que no tiene un significado específico en la normativa ${ }^{(39)}$ pero que supone un contrato por el cual quien presta el servicio, puede ser employee o worker, no posee un horario ni jornada fija, esto es, debe estar siempre a disposición y generalmente a exclusividad. De ahí sus evidentes críticas ${ }^{(40)}$, en especial la incertidumbre en saber si un día se va a trabajar o no.

Según una noticia publicada en febrero de 2015 en el diario "The Guardian"(41), más de 700,000 personas en Reino Unido (el $2.3 \%$ de los trabajadores de ese país) tenían contratado su principal trabajo bajo la modalidad de cero horas, siendo que McDonalds, por ejemplo, empleaba con este contrato al $90 \%$ de sus trabajadores en dicho país sustentando dicha opción en que su personal valora principalmente, entre otras cosas, la flexibilidad en el manejo de sus tiempos ${ }^{(42)}$. Flexibilidad que puede ser útil para algunos (pensemos en estudiantes o personas que usan este trabajo eventualmente) pero también perjudicial y hasta abusivo para quienes dependen solamente de ese trabajo, situación que puede ser muy estresante ${ }^{(43)}$. Tan grave es el problema que, en plena campaña política previa a las elecciones de marzo de 2015, el conservador David Cameron y el laborista Ed Miliband reconocieron que no podrían sobrevivir con este tipo de contrato, que si bien es precario lograba reducir las cifras de desempleo (5.6\%). De ahí que la comisión mundial sobre el futuro del trabajo resalte en su informe presentado en enero de 2019 la necesidad de que el trabajador cuente con

(38) Una síntesis de las diferentes modificaciones legislativas españolas que generaron la flexibilidad laboral de los últimos años se puede leer en Sáez Lara (2012, 221-248), quien considera que "son cada vez más fuertes los argumentos a favor de la inconstitucionalidad de una regulación legal que admite decisiones empresariales que modifiquen lo pactado en un acuerdo colectivo".

(39) Véase "Zero hours contracts: understanding the law", CIPD, 2013, 1-18, información que se puede encontrar en http://www.cipd. co.uk/binaries/zero-hours-contracts_2013-understanding-the-law.pdf (última revisión: 20 de diciembre de 2018).y también DEAKIN, Simon y MORRIS, Gillian S, "LabourLaw”, Butterworths, 2001, 254.

(40) Ver http://www.elblogsalmon.com/mundo-laboral/el-contrato-britanico-de-cero-horas-esclavitud-encubierta (última revisión: 20 de diciembre de 2018).

(41) Ver la noticia en http://www.theguardian.com/uk-news/2015/feb/25/zero-hours-contract-rise-staff-figures (última revisión: 20 de diciembre de 2018).

(42) O por lo menos eso es lo que indica la compañía en su página web. Ver al respecto el siguiente link: http://www.mcdonalds.co.uk/ ukhome/whatmakesmcdonalds/questions/work-with-us/working-hours/does-mcdonalds-use-zero-hour-contracts.html (última revisión 20 de diciembre de 2018).

(43) En la nota publicada en la edición digital del diario "El País" el 2 de mayo de 2015 ("Elecciones en Reino Unido: Trabajadores ultraflexibles") que se puede ver en el siguiente enlace: $\mathrm{http}: / /$ internacional.elpais.com/internacional/2015/05/01/actualidad/1430504838_853098.html (última revisión: 20 de diciembre de 2018) se recogen testimonios de trabajadores de Liverpool a quienes les remiten sus horarios de trabajo al inicio de cada mes o, en el otro extremo, 24 horas antes. Claro está, bajo este contrato no es complicado el despido pues simplemente el empleador no tiene que llamarte para trabajar. Asimismo, no existen los horarios: " $A$ veces entro a las dos de la tarde y no salgo hasta las seis de la mañana”. En una reciente conversación con un copiloto de una línea de aviación se nos comentó que la jornada de vuelo le es avisada un día antes. ¿Cómo poder decidir cosas de la vida con esta indefinición temporal de trabajo? 
"medidas de reglamentación apropiadas que establezcan un número mínimo de horas garantizadas y previsibles”. Asimismo, que se compense el horario variable con "una prima por un trabajo que no está garantizado y una remuneración por tiempo de espera para compensar los periodos en los que los trabajadores por hora están de guardia" (OIT 2019, 42).

Retornando a Perú, una vez fijada la jornada, el empleador puede incrementarla (se entiende que de manera permanente) a la máxima legal de manera discrecional, sin requerir autorización o acuerdo, con la sola obligación de incrementar la remuneración para pagar de manera proporcional las horas adicionales. En efecto, el artículo 3 de la ley establece:

"En centros de trabajo en que rijan jornadas menores a ocho (8) horas diarias o cuarenta y ocho (48) horas a la semana, el empleador podrá extenderlas unilateralmente hasta dichos límites, incrementando la remuneración en función al tiempo adicional. Para tal efecto se observará el criterio de remuneración ordinaria contenido en el Artículo 12 de la presente Ley."

Estamos ante una norma claramente flexible que resulta una excepción a la consideración del tiempo de trabajo como elemento esencial del contrato. Así, el trabajador inicialmente vinculado por unas horas o días a la semana (por ejemplo, un trabajador a tiempo parcial o alguien que labore de lunes a viernes) no podría negarse a trabajar más horas o días si así lo decide su empleador, quedando solamente la renuncia como solución a la nueva situación pues ni siquiera este hecho está considerado como una causal de hostilidad. En un caso extremo, el trabajador deberá dejar de estudiar, tener otro trabajo o simplemente reducir el disfrute de su tiempo libre porque su empleador legalmente lo obligaría a trabajar más tiempo, con la sola compensación de pagarle (a tarifa ordinaria) ese nuevo lapso.

Entendemos que esta disposición legal resulta contradictoria con derechos constitucionales, los previstos en la normativa internacional y también con los que regulan, en la misma norma, las variaciones de horario y jornada, pero no conocemos algún caso judicial donde se haya producido esta discusión. Ello porque tampoco es muy usual ver supuestos de ampliación de jornada determinados de manera unilateral, sino que el empleador busca cubrir esta necesidad con horas extras, con relaciones excluidas del límite máximo o, finalmente, formalizando esta modificación con un acuerdo.

Como se puede ver, en este caso el trabajador pierde una garantía de regularidad o conocimiento de su jornada por el objetivo de facilitar la administración del trabajo por parte del empleador. Consecuentemente, somos de la opinión que dicha regulación debería eliminarse, más aún cuando contradice el procedimiento previsto en el artículo 2 de la misma norma.

Para otros casos de afectación de la jornada que no sean el incremento ya descrito, por ejemplo, variaciones de días, turnos, horas, etc., la ley establece un procedimiento específico y hasta algo contradictorio.

Consideremos que la Ley de Productividad y Competitividad Laboral(44) (en adelante, la LPCL) prevé en su artículo 9 la posibilidad de que el empleador puede modificar turnos, días $\mathrm{u}$ horas de trabajo aunque respetando dos límites: la racionabilidad y las necesidades del centro de trabajo. Como vemos, no cuentan los intereses del trabajador, salvo que puedan darle contenido al primero de los límites.

La ley complementa o precisa esta facultad de modificar los aspectos vinculados al tiempo de trabajo. Si bien señala en su artículo 2 que el empleador puede:

“a) Establecer la jornada ordinaria de trabajo, diaria o semanal.

b) Establecer jornadas compensatorias de trabajo de tal forma que en algunos días la jornada ordinaria sea mayor y en otras menor de ocho horas, sin que en ningún caso la jornada ordinaria exceda en promedio de cuarenta y ocho horas por semana.

c) Reducir o ampliar el número de días de la jornada semanal del trabajo, encontrándose autorizado a prorratear las horas dentro de los restantes días de la semana, considerándose las horas prorrateadas como parte de la jornada ordinaria de trabajo, en cuyo caso ésta no podrá exceder en promedio de cuarenta y ocho horas semanales. En caso de jornadas acumulativas o atípicas, el promedio de horas trabajadas en el período correspondiente no puede superar dicho máximo.

d) Establecer, con la salvedad del Artículo 9 de la presente Ley, turnos de trabajo fijos o rotativos, los que pueden variar con el tiempo según las necesidades del centro de trabajo.

(44) Texto único ordenado del Decreto Legislativo 728, otrora ley de fomento del empleo, aprobado por Decreto Supremo 3-97-TR del 27 de marzo de 1997. 
e) Establecer y modificar horarios de trabajo ${ }^{(45)}$."

A continuación, precisa que, para que puedan proceder dichas modificaciones, el empleador debe ${ }^{(46)}$ :

- Comunicar con 8 días de anticipación al sindicato o a los representantes de los trabajadores o a los trabajadores afectados la medida a adoptarse y los motivos que la sustentan.

- Dentro de ese plazo la parte laboral puede solicitar al empleador una reunión para plantear una medida distinta a la propuesta, debiendo definir el empleador la fecha y hora de la misma. Si no hay acuerdo la ley establece que el empleador está facultado para realizar la medida propuesta, sin perjuicio del derecho de impugnación de los afectados.

El artículo 7 del reglamento de la ley(47) modifica (y si hace ello creemos que resulta ilegal) este procedimiento, haciéndolo más exigente. En efecto, se indica que la reunión debe solicitarse a los 3 días de recibida la comunicación y que dicha solicitud debe contener la medida distinta propuesta y su sustento, justificando las razones de la oposición a la decisión del empleador. Recién con esta solicitud el empleador citará a la reunión dentro de los 3 días siguientes.

Consideramos que el reglamento está modificando la ley porque nada impide que en la reunión el empleador pueda recién conocer la propuesta alternativa de la variación, más aún cuando 3 días parecería un plazo muy corto para elaborar una propuesta seria.
- Dentro de los 10 días siguientes a la adopción de la medida, la parte laboral puede impugnarla ante la autoridad administrativa de trabajo para que se pronuncie sobre su procedencia en un plazo no mayor de 10 días hábiles en base a los argumentos y evidencias que propongan las partes.

El reglamento también indica que si la modificación se genera por un caso fortuito o un supuesto de fuerza mayor solamente es necesario que el trabajador involucrado la acepte por escrito, lo cual no establece algo nuevo.

De otro lado, la disminución de turnos, días u horas de trabajo pactada se prevé como una medida para coadyuvar a la continuidad de las actividades económicas de la empresa durante el procedimiento previo a la extinción de los contratos de trabajo por las causas objetivas generadas por motivos económicos, tecnológicos, estructurales o análogos según lo prevé el literal b) del artículo 48 de la LPCL $^{(48)}$.

Por tanto resulta curioso que ante medidas claramente objetivas como las que sustentarían una medida de cese colectivo

(45) Este literal debe leerse junto con el artículo 6 de la ley que señala:

Artículo 6.- Es facultad del empleador establecer el horario de trabajo, entendiéndose por tal la hora de ingreso y salida, sin perjuicio de lo establecido en el Artículo 2 inciso d). Igualmente está facultado a modificar el horario de trabajo sin alterar el número de horas trabajadas. Si la modificación colectiva de horario es mayor a una hora y la mayoría de los trabajadores no estuviera de acuerdo, podrán acudir a la Autoridad Administrativa de Trabajo para que se pronuncie sobre la procedencia de la medida en un plazo no mayor de diez (10) días hábiles, en base a los argumentos y evidencias que se propongan las partes. La resolución es apelable dentro del tercer día. Si la modificación tiene carácter individual, la impugnación de la medida por el trabajador se efectuará conforme a las disposiciones de la Ley Orgánica del Poder Judicial.

Como se puede ver, estamos ante regulaciones contradictorias en una misma norma que hasta la fecha no han sido corregidas

(46) Este procedimiento no estaba originalmente previsto y fue incluido casi seis años después de vigente la norma original (Decreto Legislativo 854 de octubre de 1996) mediante Ley 27671 publicada el 21 de febrero de 2002. La norma original ofrecía mayor discrecionalidad del empleador para realizar las variaciones, regulación que todavía se mantiene en el artículo 3 de la ley antes comentado, así como en lo previsto para la modificación del horario de trabajo (artículo 6 de la ley arriba citada), que posee otro procedimiento de impugnación cuando la modificación es mayor a una hora y afecta a más de un trabajador.

(47) Aprobado por Decreto Supremo 8-2002-TR:

Artículo 7.- La solicitud del sindicato, o a falta de éste de los representantes de los trabajadores, o en su defecto, de los trabajadores afectados, para llevar a cabo la reunión a que hace referencia el segundo párrafo, inciso 2) del Artículo 2 de la Ley deberá realizarse dentro de los tres días siguientes de recibida la comunicación del empleador. En dicha solicitud se deberá sustentar la medida distinta a la propuesta por el empleador y justificar las razones de la oposición a la medida planteada por éste. Recibida la solicitud, el empleador citará a la correspondiente reunión dentro de los tres días siguientes. De ocurrir un supuesto de caso fortuito o fuerza mayor que haga indispensable introducir alguna de las modificaciones previstas en el numeral 1) del Artículo 2 de la Ley será suficiente para proceder a ellas, contar con la aceptación escrita del o los trabajadores involucrados.

(48) "La empresa con el sindicato, o en su defecto con los trabajadores afectados o sus representantes, entablarán negociaciones para acordar las condiciones de la terminación de los contratos de trabajo o las medidas que puedan adoptarse para evitar o limitar el cese de personal. Entre tales medidas pueden estar la suspensión temporal de las labores, en forma total o parcial; la disminución de turnos, días u horas de trabajo la modificación de las condiciones de trabajo; la revisión de las condiciones colectivas vigentes; y cualesquiera otras que puedan coadyuvar a la continuidad de las actividades económicas de la empresa. El acuerdo que adopten tendrá fuerza vinculante;" 
se permita la disminución de turnos, días u horas de trabajo siempre que haya acuerdo entre las partes pero para otros supuestos de variación del tiempo de trabajo donde no existe una emergencia económica por ejemplo solamente sea necesaria la voluntad del empleador, quedándole al trabajador la posibilidad de reclamo pero en forma posterior y la decisión en manos de un tercero.

Por tanto, notamos que en este tema la normativa peruana le da una clara preferencia al empleador pues la validez de su medida se presumirá hasta que, si la parte afectada la cuestiona oportunamente, la autoridad administrativa de trabajo resuelva. Tal como ocurría en la década de los setenta, será un funcionario público quien decida algo tan importante para las partes como lo es una variación del tiempo de trabajo, la misma que debe ser inmediatamente acatada por el trabajador cuando de repente lo ideal sería que fuera un inspector o un juez de trabajo quien evalúe cada caso.

Asimismo, sería recomendable que este derecho fuera mejor regulado considerando la gravedad de la variación pues posee diferente impacto la modificación del horario que el cambio de un turno o la creación de un nuevo día de trabajo, siendo que para las situaciones más severas solamente se debería admitir la modificación si es acordada por las partes. Asimismo, debería unificarse el procedimiento de impugnación previsto legalmente para el horario junto con el aplicable a cualquier otra variación. Tareas que preferimos correspondan ser asumidas por los actores sociales antes que por terceros.

\section{Conclusiones}

1. El tiempo de trabajo es un elemento esencial del contrato laboral al condicionar el aspecto temporal del objeto de dicho contrato y al ser un derecho fundamental reconocido a nivel nacional e internacional.

2. La protección de la seguridad y la salud de las personas que trabajan sustentan la limitación de la jornada de trabajo.

3. La normativa peruana mantiene los límites del tiempo de trabajo existentes hace cien años. No reconoce varios de los derechos presentes en normas internacionales que ha ratificado y, peor aún, excluye a ciertos trabajadores de este derecho.

4. Es necesaria una reformulación de regulación del tiempo de trabajo, en especial de los límites a la jornada de trabajo, tomando en cuenta las nuevas formas de trabajo existentes.

5. La jornada y el horario de trabajo deberían estar claramente establecidas en la oferta de cada puesto de trabajo, y resultar excepcional su variación unilateral.

6. El procedimiento de variación de jornada u horario previsto en la legislación peruana debería adecuarse a otras disposiciones vigentes en la misma normativa que resultan contradictorias.

7. Si no existe un límite al tiempo de trabajo, no se puede tener tiempo libre.

\section{Referencias bibliográficas}

Argüelles Blanco, Ana Rosa. 2012. La ordenación sostenible del tiempo de trabajo: luces y sombras de las últimas reformas laborales. Revista Internacional de Organizaciones 8 (junio): 11-29. DOI: 10.17345/rio8.11-29

Basadre, Jorge. 1963. Historia de la república del Perú, tomos VII y VIII. Lima: Ediciones Historia.

Bregman, Rutger. 2017. Utopía para realistas. Título original: Utopia for Realists. Traducción de Javier Guerrero Gimeno. Barcelona: Ediciones Salamandra.

Deakin, Simon y Morris, Gillian. 2001. Labour Law. Reino Unido: Butterworths.

Engels, Friedrich y Marx, Karl. 1971. La sagrada familia. Argentina: Editorial Claridad.

Ferriss, Timothy. 2016. La semana laboral de 4 horas. RBA Libros.

Frayne, David. 2017. El rechazo del trabajo. Teoría y práctica de la resistencia al trabajo. Traducción de Cristina Piña Aldao. Madrid: Akal.

Grau Gómez, Luis y Martínez Neira, Manuel. 2011. Resolución del Tribunal Supremo: Lochner v. New York, 198 U.S. 45 (1905), en el curso Historia del Constitucionalismo Americano (2011). http://ocw.uc3m.es/historia-del-derecho/ historia-del-constitucionalismo-americano/ otros-recursos-2/tema-6-la-epocaprogresista-y-el-new-deal/resolucion-deltribunal-supremo-lochner-v.-new-york-198u.s.-45-1905/view

Harari, Yuval. 2018. 21 lecciones para el siglo XXI. Traducción de Joandomènec Ros. Barcelona: Debate.

Hobsbawm, Eric. 2011. La era de la revolución: 1789-1848. Buenos Aires: Editorial Crítica. 
Lanfranco González, María Fernanda. 2013. La teoría sobre la naturaleza del hombre y la sociedad en el pensamiento de Robert Owen como base del socialismo británico (1813-1816). Revista Historia Crítica 50 (mayo-agosto). DOI: doi.org/10.7440/ histcrit50.2013.09

Lévano, César. 1967. La verdadera historia de la jornada de las ocho horas en el Perú. Lima.

Llosa, Susana. 2015. Empleados empresarios ¿cómo actúa un trabajador con la mentalidad del dueño de la compañía? Revista $G$ de Gestión, marzo.

Martínez Yañez, Nora. 2011. El régimen jurídico de la disponibilidad horaria. Navarra: Thomson Reuters-Aranzadi.

Marx, Karl. 2010. El capital. Alianza Editorial.

Molina Perez de Valenzuela, Martín. 1950. Breve estudio comparativo de las legislaciones del trabajo de Chile y Perú. En Memorias de licenciados. Derecho del Trabajo, tomo III, volumen IX, Universidad de Chile, 259-394. Santiago: Editorial Jurídica de Chile.

Monereo Perez, José Luis y Gorelli Hernández, Juan. 2009. Tiempo de trabajo y ciclos vitales, estudio crítico del modelo normativo. Granada: Editorial Comares.

Organización Internacional del Trabajo. 2019. Trabajar para un futuro más prometedor. Ginebra.

Palomeque, Manuel y Álvarez, Manuel. 2009. Derecho del trabajo. 17ma edición. Madrid: Editorial Universitaria Ramón Areces.

Pasco Cosmópolis, Mario. 1993. La jornada de trabajo. En Jornada de trabajo y descansos remunerados, coord. Néstor de Buen. México: Editorial Porrúa.

Pérez del Castillo, Santiago. 2013. Manual práctico de normas laborales. 13ra edición. Fundación de Cultura Universitario.

Sáez Lara, Carmen. 2012. Medidas de flexibilidad interna: movilidad funcional, geográfica y modificaciones sustanciales de condiciones de trabajo. Temas Laborales. Revista andaluza de trabajo y bienestar social 115: 221-248.
Slagstad, Rune y Elster, Jon. 1999. Constitucionalismo y democracia. México: Fondo de Cultura Económica.

Stein, Steve. 1986. Lima obrera 1900-1930. Tomo I. Lima: El Virrey.

Tristán, Flora. 2011. Unión obrera. Lima: Centro de la Mujer Peruana Flora Tristán y Fondo Editorial de la Universidad Nacional Mayor de San Marcos.

2006. El tour de Francia (1843-1844). Lima: Centro de la Mujer Peruana Flora Tristán, Embajada de Francia en Perú, Instituto Francés de Estudios Andinos y Fondo Editorial de la Universidad Nacional Mayor de San Marcos.

Ulloa Millares, Daniel. 2013. La titularidad de los derechos constitucionales laborales y su tratamiento legal: ideas sobre el concepto de trabajador previsto en la Constitución y las relaciones laborales legalmente excluidas. Revista Derecho \& Sociedad 40 (junio): pp. 101-111.

2016. El olvidado o relegado derecho humano al disfrute del tiempo libre. Revista Derecho \& Sociedad 47 (octubre): pp. 333-347.

Toyama Miyagusuku, Jorge. 2015. Espacios para la adaptación flexible del tiempo de trabajo y las condiciones laborales en el ordenamiento laboral peruano. Conferencia presentada en el "III Curso Internacional de Estudios Avanzados en Derecho Social", del 11 de mayo al 22 de mayo, en la Pontificia Universidad Católica del Perú, Lima.

Enlaces de páginas web (última revisión: 20 de diciembre de 2018):

http://www.bbc.com/news/business-30540538.

https://elpais.com/ccaa/2018/12/28/madrid/1545991834_ 345040.html.

http://www.cipd.co.uk/binaries/zero-hours-contracts_2013understanding-the-law.pdf.

http://www.elblogsalmon.com/mundo-laboral/el-contratobritanico-de-cero-horas-esclavitud-encubierta.

http://www.theguardian.com/uk-news/2015/feb/25/zero-hourscontract-rise-staff-figures.

http://www.mcdonalds.co.uk/ukhome/whatmakesmcdonalds/ questions/work-with-us/working-hours/does-mcdonalds-usezero-hour-contracts.html.

http://internacional.elpais.com/internacional/2015/05/01/ actualidad/1430504838_853098.html.

https://www.lainformacion.com/mundo/japon-se-pone-manosa-la-obra-y-reforma-una-ley-para-eliminar-el-exceso-detrabajo/6351369/. 